\title{
Behavioural and temperamental characteristics of children and adolescents suffering from primary headache
}

\author{
L Mazzone ${ }^{1}$, B Vitiello ${ }^{2}$, G Incorpora ${ }^{1}$ \& D Mazzone ${ }^{1}$ \\ ${ }^{1}$ Division of Child Neurology and Psychiatry, Department of Paediatrics, University of Catania, Catania, Italy, and ${ }^{2}$ Division of Services and \\ Intervention Research, NIMH, Bethesda, MD, USA
}

\section{Cephalalgia}

Mazzone L, Vitiello B, Incorpora G \& Mazzone D. Behavioural and temperamental characteristics of children and adolescents suffering from primary headache. Cephalalgia 2006; 26:194-201. London. ISSN 0333-1024

To examine indices of behavioural and emotional problems and temperamental traits in clinically referred children and adolescents suffering from tension headache or migraine. Headache in childhood and adolescence ( $<18$ years) has been associated with the presence of behavioural and emotional difficulties, but limited data are available on the relationship between these problems and different types of headache. Clinically referred children and adolescents $(N=114), 6-16$ years of age, suffering from primary headache according to the diagnostic criteria of the International Headache Society, 47 with tension-type headache (TH) and 67 with migraine (M), and 36 normal controls without headache (NC) were assessed using the Parent Child Behaviour Checklist (CBCL), Children's Depression Inventory (CDI), Multidimensional Anxiety Scale for Children (MASC), Conner's Parent Rating Scale (CPRS), and Emotionality-Activity-Sociability-Shyness Scale (EAS). Psychological and personality self-rating assessments were obtained also on the children's parents and siblings. Although most headache patients had scores within the normative non-pathological range, both $\mathrm{TH}$ and $\mathrm{M}$ patients had higher CBCL total, internalizing, and externalizing scores than $\mathrm{NC}(P<0.001)$, and $\mathrm{TH}$ patients had higher scores than $\mathrm{M}$ patients. TH and $\mathrm{M}$ had higher CDI and MASC scores than NC $(P<0.05)$, with no difference between the headache groups. TH patients had higher Emotionality and Shyness scores, and lower Sociability scores than $\mathrm{M}$ patients. Clinically referred children and adolescents with $\mathrm{TH}$ and $\mathrm{M}$ had higher scores of behavioural and emotional symptoms, both of internalizing and externalizing type, than normal peers. The TH group had greater psychological and temperamental difficulties than the $\mathrm{M}$ group. $\square$ Adolescents, children, headache, mental health, migraine, temperament

Luigi Mazzone MD, Department of Paediatrics, Azienda Policlinico Università, Via S. Sofia, 78, 95100 Catania, Italy. Tel. + 39095378 2436, e-mail mazzone@mbox.unict.it Received 13 October 2004, accepted 12 May 2005

\section{Introduction}

Headache is common among children and adolescents. Epidemiological studies suggest that 10-30\% of children and adolescents report weekly or daily headaches (1). Migraine occurs in 3-15\% of children (2-5) while $9-33 \%$ of patients suffer from nonmigrainous headache at least monthly $(4,6)$. The Headache Classification ad hoc Committee of the International Headache Society (IHS) (1988) includes different types of headache (7). Among primary headache, a distinction is made between tensiontype headache $(\mathrm{TH})$ and migraine $(\mathrm{M})$. In childhood, headache can be the expression of psychological difficulties, such as anxiety and depression, and stressful life events have been frequently implicated in the onset, exacerbation, and maintenance of headache (8). Conversely, headache itself can be a source of stress, leading to functional impairment, which can cause anxiety in both patients and families (9). The 
relationship between headache and psychological difficulties has been the object of considerable investigation especially in adults, but also in children, although the latter has received less attention $(1,10$ $14)$.

In clinical samples, anxiety and depression symptoms have been found to be associated with $\mathrm{M}$, but not with $\mathrm{TH}$ in children (14), a finding that is consistent with epidemiological studies in adults $(15,16)$. Recently, in a population-based study in Finnish children, levels of internalizing symptoms, and somatic symptoms in particular, were increased among $\mathrm{M}$ children, but not among $\mathrm{TH}$ children, compared with non-headache children (12). Taken together, these data seem to indicate that anxiety, depression and somatic symptoms are more specifically related to $\mathrm{M}$ than to TH. An association between headache and certain personality traits or psychiatric disorders has also been reported in adults (17-20). In children, specific traits, such as rigidity and emotional inhibition, have been found among children with idiopathic headache (21).

The purpose of our study was to examine further the presence of behavioural and emotional symptoms among clinically referred children. Because of the relatively small sample size, this investigation was intended to be more exploratory than hypothesis testing. In particular our aims were:

1 To examine the association between headache and ratings of behavioural and emotional difficulties. It was predicted that children who were clinically referred because of primary headache would have higher levels of psychological symptoms in general, and depression, anxiety and somatic symptoms in particular, compared with children without headache.

2 To examine the possible specific association between type of headache and psychological symptoms. It was predicted that the association with internalizing symptoms in general, and anxiety, depression and somatic symptoms in particular, would be more evident among $\mathrm{M}$ children than TH children.

3 To examine the relationship between temperament and headache and its subtypes. It was predicted that children with headache would display traits of greater shyness, higher emotionality and lower sociability than non-headache children.

4 To examine temperament in relatives of cephalalgic children compared with relatives of nonheadache children. It was predicted that relatives of cephalalgic children would have higher rates of shyness, higher emotionality and lower sociability than relatives of non-headache children.

\section{Methods}

\section{Subjects}

Children and adolescents, age $6-16$ years, referred to the headache clinic of Child and Adolescent Neuropsychiatry of the Paediatric Department at the University of Catania, Italy, during the years 2002 and 2003, and meeting diagnostic criteria for TH or M according to the 1988 IHS criteria (7), were enrolled in this study. Patients were diagnosed according to the 1988 IHS criteria (7), as the more recent 2004 ICHD II was published after the data collection was completed (22). Normal controls (NC) were randomly selected from a database of healthy children attending a well-being paediatric clinic for routine checks.

Parents and siblings of the subjects participating in this study were also invited to participate in the psychological and personality trait assessments. Parental consent was obtained for each subject, and each child assented to participation.

\section{Assessments}

Each patient received a comprehensive physical and neurological assessment, including EEG, and ophthalmological examination. In a few cases, magnetic resonance imaging (MRI) was also obtained. Two child neuropsychiatrists trained in the diagnostic criteria set by the 1988 IHS (7) classified the patients as suffering from $\mathrm{TH}$ or $\mathrm{M}$, with or without aura. The psychological evaluation included administration of the following instruments:

(i) The Child Behaviour Checklist (CBCL), which is a 113-item questionnaire completed by the parents. The CBCL rates child behavioural and emotional problems both globally and along the two dimensions of 'internalizing' symptoms composed of subscales Anxious/Depressed, Withdrawn, and Somatic Complaints, such as anxiety and depression, and 'externalizing' symptoms, such as aggression and hyperactivity. Raw scores of each clinical factor were transformed to $\mathrm{T}$ scores based on published norms, and scores of $\geq 70$ were considered indicative of clinical impairment. Scores for specific subscales were also computed $(23,24)$.

(ii) The Children's Depression Inventory (CDI), which was completed by the child, was used to 
rate symptoms of depression (25). The CDI is a self-rating scale that consists of 27 items scored on a three-point scale ( 0 , absent; 1 , moderate; 2 , severe) reflecting growing severity of symptoms. Total scores range from 0 to 54 . A 19-point cut-off indicates the ideal threshold discriminating children at risk of depression from nondepressed children.

(iii) The Multidimensional Anxiety Scale for Children (MASC), which was also completed by the child to score symptoms of anxiety. The MASC is a 39-item four-point Likert-style self-report scale that has undergone extensive psychometric evaluation (26). MASC main and subfactors include (a) physical symptoms (tense/restless and somatic/autonomic), (b) harm avoidance (anxious coping and perfectionism), (c) social anxiety (humiliation/rejection and public performance fears), and (d) separation anxiety. The raw scores were converted into standard $\mathrm{T}$ scores.

(iv) The Conner's Parent Rating Scale (CPRS), which was completed by the parents. We applied the latest revision of the CPRS, with a 27-item short form (CPRS-R:S) (27). Each item is a brief description of a potentially problematic behaviour that the parent rates on a four-point Likert-type scale $(1$, not at all; 2 , just a little; 3 , pretty much; and 4 , very much). All scores for items loading on a particular scale are summed to produce a raw scale score. Raw scores were used in the absence of norms for the Italian population.

(v) The Emotionality, Activity, Sociability and Shyness Scale for Childhood (EAS) was completed by the children, their parents and siblings, to rate four temperament traits: Emotionality (the tendency to become easily upset), Activity (the tendency to be restless), Sociability (the tendency to prefer the presence of other over solitude), and Shyness (uneasiness in novel or unfamiliar social situations) (28). For each child, parents were asked to rate each statement on a 'five-point' Likert scale, ranging from 0 (not characteristic or typical of the child) to 5 (very characteristic or typical of the child). Mothers and fathers were asked to rate each child; the child scores were obtained by averaging parents' ratings. Higher scores on the EAS do not necessarily represent greater dysfunction, but subjects with higher scores have been found to be more likely to suffer from emotional problems (28).

\section{Data analysis}

Data were analysed with standard descriptive statistics: $\chi^{2}$ test, analysis of variance and non-parametric tests, as indicated in the text and tables. A two-end $P$-value of $<0.05$ was used as the cut-off point of statistical significance. When multiple tests were conducted within the same measure (e.g. in the case of the CBCL), $P$ was corrected using a Bonferroni's method by multiplying the obtained $P$ by the number of tests. However, when an omnibus test was significant at $P<0.05$, explanatory pairwise comparisons were conducted without further correction of $P$.

\section{Results}

\section{Clinical characteristics}

A total of 114 patients with chronic headache (61 males and 53 females; age range 6-16 years; mean age \pm SD $10.66 \pm 2.05$ ) were studied. Of them, 47 (41\%) had TH and $67(59 \%)$ M. Thirty-six subjects were included in the NC group. Demographic and clinical characteristics of the 150 children participating in the study are summarized in Table 1 . There was no significant difference between the $\mathrm{TH}$ $(N=47), \mathrm{M}(N=67)$, and non-headache NC children

Table 1 Subject demographics and clinical characteristics

\begin{tabular}{|c|c|c|c|c|}
\hline Groups & $\begin{array}{l}\text { Tension headache } \\
(N=47)\end{array}$ & $\begin{array}{l}\text { Migraine } \\
(N=67)\end{array}$ & $\begin{array}{l}\text { Normal controls } \\
(N=36)\end{array}$ & $P^{\mathrm{a}}$ \\
\hline Males/females & $28 / 19$ & $33 / 34$ & $20 / 16$ & NS \\
\hline Age (mean $\pm \mathrm{SD})$ & $11.11 \pm 1.59$ & $11.13 \pm 1.90$ & $10.35 \pm 2.35$ & NS \\
\hline Age at headache onset (mean \pm SD) & $9.27 \pm 2.26$ & $8.73 \pm 2.36$ & - & NS \\
\hline First born & $28(59.5 \%)$ & $34(50.7 \%)$ & $12(33.3 \%)$ & NS \\
\hline Pre-, peri-, or postbirth complications & $19(40.4 \%)$ & $21(31.3 \%)$ & $4(11.1 \%)$ & $<0.05$ \\
\hline Family history of headache & $34(74.4 \%)$ & $47(70 \%)$ & $5(13.8 \%)$ & $<0.001$ \\
\hline Family history of psychiatric disorders & $20(42.5 \%)$ & $10(14.9 \%)$ & $4(11.1 \%)$ & $<0.001$ \\
\hline
\end{tabular}

${ }^{a} \chi^{2}$ test for categorical variables and ANOVA for continuous variables. NS indicates $P>0.05$. 
$(N=36)$ as to age and gender distribution. About three-quarters of the children with headache had a family history of headache, compared with only $13.8 \%$ of normal controls. Headache children were also more likely to have had pre-, peri- or immediately postbirth complications. A family history of psychiatric disorders was more common among headache patients, especially the TH group. The socioeconomic status of families was similar in the groups.

In addition to headache, some patients suffered from other conditions, most commonly primary enuresis $(N=18)$, gastric pain $(N=8)$, obsessivecompulsive disorder $(N=6)$, panic attacks $(N=4)$, and tics $(N=4)$. These conditions were equally distributed between $\mathrm{TH}$ and $\mathrm{M}$.

All the subjects had normal neurological and ophthalmological examinations. A few subjects had brain MRI or EEG tracing, which did not reveal any clinically significant abnormalities.

\section{Psychological symptom ratings}

Compared with NC, both $\mathrm{TH}$ and $\mathrm{M}$ had significantly higher scores on all the administered rating scales (CBCL, CDI, and MASC) except for the CPRS, whose mean score was elevated only for the $\mathrm{TH}$, but not the $\mathrm{M}$ children (Table 2). The $\mathrm{TH}$ group had higher CBCL (total, internalizing and externalizing) and CPRS scores than the M group. Analysis of the three factors of the MASC indicated higher T scores of Physical Symptoms between TH $(62.58 \pm 7.60)$ and M $(55.76 \pm 9.92)$ than NC $(42.38 \pm 6.21, P<0.001)$ with no statistically significant differences between $\mathrm{TH}$ and M. Likewise, Harm Avoidance scores were greater in $\mathrm{TH}(50.06 \pm 11.79)$ and $\mathrm{M}(48.01 \pm 9.74)$ than in NC $(35.07 \pm 9.42, P<0.001)$, with no differences between $\mathrm{TH}$ and $\mathrm{M}$. Social Anxiety scores, however, were greater in $\mathrm{TH}(62.54 \pm 11.28)$ than $\mathrm{M}$ (53.21 $\pm 10.04, P<0.001)$, with both headache groups being higher than NC $(39.82 \pm 12.03, P<0.001)$, as shown in Fig. 1.

Most of the patients, however, had scores within the non-pathological range, according to established norms (Table 3). A higher proportion of TH patients had pathological CBCL total and internalizing scales than $\mathrm{NC}$, while the $\mathrm{M}$ group had a higher rate of children in the pathological range only for the CBCL internalizing scale. The number of patients with pathological scores on the CBCL externalizing scale,

Table 2 Psychological and temperamental ratings (mean \pm SD)

\begin{tabular}{|c|c|c|c|c|c|c|}
\hline & \multirow{2}{*}{$\begin{array}{l}\text { Tension } \\
\text { headache }(\mathrm{TH}) \\
(N=47)\end{array}$} & \multirow{2}{*}{$\begin{array}{l}\text { Migraine (M) } \\
(N=67)\end{array}$} & \multirow{2}{*}{$\begin{array}{l}\text { Normal } \\
\text { controls (NC) } \\
(N=36)\end{array}$} & \multicolumn{2}{|c|}{ ANOVA } & \multirow{2}{*}{$\begin{array}{l}\text { Pairwise contrasts } \\
{ }^{\text {h }} \\
{ }^{*} P<0.05 \\
{ }^{* * *} P<0.01 \\
{ }^{* *} 0.001\end{array}$} \\
\hline & & & & $F$ & $P^{\mathrm{i}}$ & \\
\hline CBCL Total $^{\mathrm{a}}$ & $59.65 \pm 9.17$ & $52.62 \pm 8.59$ & $47.35 \pm 8.62$ & 20.68 & $<0.001$ & $\mathrm{TH}>^{* * *} \mathrm{NC} ; \mathrm{M}>^{* *} \mathrm{NC} ; \mathrm{TH}>^{* * *} \mathrm{M}$ \\
\hline CBCL Intern. ${ }^{\mathrm{b}}$ & $66.03 \pm 10.79$ & $61.59 \pm 9.87$ & $51.02 \pm 7.21$ & 25.67 & $<0.001$ & $\mathrm{TH}>{ }^{* * *} \mathrm{NC} ; \mathrm{M}>{ }^{* * *} \mathrm{NC} ; \mathrm{TH}>{ }^{*} \mathrm{M}$ \\
\hline CBCL Extern. ${ }^{c}$ & $57.59 \pm 8.89$ & $53.67 \pm 6.78$ & $49.12 \pm 3.06$ & 15.39 & $<0.001$ & $\mathrm{TH}>{ }^{* * *} \mathrm{NC} ; \mathrm{M}>{ }^{* * *} \mathrm{NC} ; \mathrm{TH}>{ }^{*} \mathrm{M}$ \\
\hline $\mathrm{CDI}^{\mathrm{d}}$ & $11.00 \pm 6.72$ & $9.75 \pm 6.47$ & $7.20 \pm 1.14$ & 4.52 & $<0.05$ & $\mathrm{TH}>{ }^{*} \mathrm{NC} ; \mathrm{M}>{ }^{*} \mathrm{NC} ; \mathrm{TH}=\mathrm{M}$ \\
\hline MASC $^{\mathrm{e}}$ & $46.40 \pm 18.49$ & $41.77 \pm 13.90$ & $36.00 \pm 6.06$ & 5.45 & $<0.001$ & $\mathrm{TH}>{ }^{*} \mathrm{NC} ; \mathrm{M}>{ }^{*} \mathrm{NC} ; \mathrm{TH}=\mathrm{M}$ \\
\hline $\mathrm{CPRS}^{\mathrm{f}}$ & $25.07 \pm 16.34$ & $16.38 \pm 14.46$ & $14.30 \pm 2.75$ & 8.27 & $<0.0001$ & $\mathrm{TH}>{ }^{* *} \mathrm{NC} ; \mathrm{M}=\mathrm{NC} ; \mathrm{TH}>{ }^{* *} \mathrm{M}$ \\
\hline \multicolumn{7}{|l|}{ EAS $^{g}$} \\
\hline Emotionality & $2.70 \pm 0.70$ & $2.28 \pm 0.86$ & $2.11 \pm 0.54$ & 7.29 & $<0.001$ & $\mathrm{TH}>{ }^{* *} \mathrm{NC} ; \mathrm{M}=\mathrm{NC} ; \mathrm{TH}>{ }^{* *} \mathrm{M}$ \\
\hline Activity & $3.64 \pm 0.88$ & $3.89 \pm 0.74$ & $3.61 \pm 0.42$ & 4.00 & NS & \\
\hline Sociability & $3.48 \pm 0.65$ & $3.93 \pm 0.67$ & $3.54 \pm 0.39$ & 9.11 & $<0.001$ & $\mathrm{TH}=\mathrm{NC} ; \mathrm{M}>^{* *} \mathrm{NC} ; \mathrm{M}>^{* *} \mathrm{TH}$ \\
\hline Shyness & $2.54 \pm 0.96$ & $2.12 \pm 1.00$ & $1.96 \pm 0.49$ & 4.95 & $<0.05$ & $\mathrm{TH}>{ }^{* *} \mathrm{NC} ; \mathrm{M}=\mathrm{NC} ; \mathrm{TH}>{ }^{*} \mathrm{M}$ \\
\hline
\end{tabular}

aParent Child Behaviour Checklist Total Score (T-scores).

bParent Child Behaviour Checklist Internalizing Score (T-scores).

'Parent Child Behaviour Checklist Externalizing Score (T-scores).

${ }^{\mathrm{d} C h i l d r e n ' s ~ D e p r e s s i o n ~ I n v e n t o r y ~(r a w ~ s c o r e s) . ~}$

eMultidimensional Anxiety Scale for Children (T-scores).

${ }^{\text {fC}}$ Conner's Parent Rating Scale (raw scores).

'Emotionality-Activity-Sociability-Shyness Scale (raw scores).

hPairwise contrasts were conducted only if the overall $P$ was statistically significant.

${ }^{\mathrm{i}}$ In case of multiple comparisons within each scale (i.e. CBCL and EAS), a Bonferroni correction was applied by multiplying the $P$ by the number of comparisons. 
Table 3 Number of children with scores in the pathological range

\begin{tabular}{|c|c|c|c|c|c|}
\hline & $\begin{array}{l}\text { Tension headache } \\
(N=47) \\
N\end{array}$ & $\begin{array}{l}\text { Migraine } \\
(N=67) \\
N\end{array}$ & $\begin{array}{l}\text { Normal controls } \\
(N=36) \\
N\end{array}$ & $\begin{array}{l}\text { Overall } \\
P^{a}\end{array}$ & $\begin{array}{l}\text { Pairwise contrasts }{ }^{\mathrm{b}} \\
{ }^{*} P<0.05 \\
{ }^{* *} P<0.01\end{array}$ \\
\hline CBCL Total & $16(34 \%)$ & $13(23 \%)$ & $1(3 \%)$ & $<0.01$ & $\mathrm{TH}>{ }^{*} \mathrm{NC} ; \mathrm{M}=\mathrm{NC} ; \mathrm{TH}=\mathrm{M}$ \\
\hline CBCL Inter. & $20(42 \%)$ & $22(33 \%)$ & $0(0 \%)$ & $<0.01$ & $\mathrm{TH}>^{* *} \mathrm{NC} ; \mathrm{M}>^{* *} \mathrm{NC} ; \mathrm{TH}=\mathrm{M}$ \\
\hline CBCL Extern. & $9(19 \%)$ & $6(9 \%)$ & $1(3 \%)$ & NS & \\
\hline CDI & $6(13 \%)$ & $7(10 \%)$ & $0(0 \%)$ & NS & \\
\hline CPRS & $12(25 \%)$ & $9(13 \%)$ & $3(8 \%)$ & NS & \\
\hline
\end{tabular}

${ }^{\mathrm{a}} \chi^{2}$ test with Yates' adjustment or Fisher's exact test as applicable; $P$ for the three CBCL tests was Bonferroni corrected for multiple comparisons; NS, not statistically significant.

${ }^{b}$ Pairwise contrasts were conducted only if the overall $P$ was statistically significant.

Table 4 Family temperament scores (mean scores and standard deviation of EAS)

\begin{tabular}{|c|c|c|c|c|c|}
\hline & $\begin{array}{l}\text { Tension } \\
\text { headache } \\
(\mathrm{TH})\end{array}$ & $\begin{array}{l}\text { Migraine } \\
\text { (M) }\end{array}$ & $\begin{array}{l}\text { Normal } \\
\text { controls } \\
(\mathrm{NC})\end{array}$ & $\begin{array}{l}\text { Overall } \\
P\end{array}$ & $\begin{array}{l}\text { Pairwise contrasts }{ }^{\mathrm{a}} \\
{ }^{*} P<0.05 \\
* * P<0.01 \\
* * * P<0.001\end{array}$ \\
\hline Mothers & $N=47$ & $N=67$ & $N=25$ & & \\
\hline Emotionality & $2.83 \pm 0.46$ & $2.39 \pm 0.51$ & $2.41 \pm 0.27$ & $<0.01$ & $\mathrm{TH}>{ }^{* * *} \mathrm{M}=\mathrm{NC} ; \mathrm{TH}>{ }^{* * *} \mathrm{NC}$ \\
\hline Activity & $2.95 \pm 0.61$ & $3.16 \pm 0.32$ & $3.37 \pm 0.28$ & $<0.01$ & $\mathrm{TH}<{ }^{* * *} \mathrm{NC} ; \mathrm{M}<{ }^{* *} \mathrm{NC} ; \mathrm{TH}<{ }^{* * *} \mathrm{M}$ \\
\hline Sociability & $3.27 \pm 0.53$ & $3.35 \pm 0.38$ & $3.44 \pm 0.47$ & NS & \\
\hline Fathers & $N=40$ & $N=58$ & $N=22$ & & \\
\hline Emotionality & $2.62 \pm 0.82$ & $2.41 \pm 0.42$ & $2.21 \pm 0.38$ & NS & \\
\hline Activity & $3.45 \pm 0.46$ & $3.30 \pm 0.49$ & $3.05 \pm 0.25$ & $<0.05$ & $\mathrm{TH}>{ }^{* * *} \mathrm{NC} ; \mathrm{M}>{ }^{*} \mathrm{NC} ; \mathrm{TH}=\mathrm{M}$ \\
\hline Sociability & $3.24 \pm 0.48$ & $3.39 \pm 0.61$ & $3.30 \pm 0.42$ & NS & \\
\hline Siblings & $N=32$ & $N=47$ & $N=19$ & & \\
\hline Emotionality & $2.70 \pm 0.98$ & $2.43 \pm 0.45$ & $2.14 \pm 0.55$ & NS & \\
\hline Activity & $3.12 \pm 0.93$ & $3.44 \pm 0.58$ & $3.38 \pm 0.29$ & 0.117 & \\
\hline Sociability & $3.28 \pm 1.02$ & $3.33 \pm 0.68$ & $3.51 \pm 0.46$ & 0.580 & \\
\hline Shyness & $2.64 \pm 0.98$ & $2.48 \pm 0.52$ & $2.11 \pm 0.66$ & NS & \\
\hline
\end{tabular}

Application procedures (APs) were Bonferroni corrected for multiple comparisons by multiplying the $P$ by the number of comparisons. Pairwise contrasts were conducted only if the overall $P$ was statistically significant. The sign ' $=$ ' indicates that the contrast is not significant at $P<0.05$.

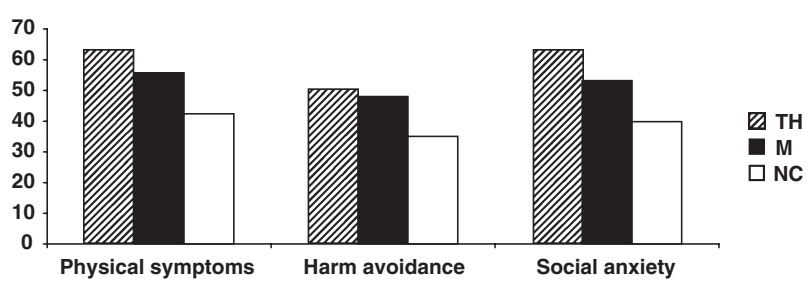

Figure 1 Multidimensional Anxiety Scale subscores (mean T-scores). TH, Tension headache; M, migraine; NC, normal controls. Significant group differences for each subscale (ANOVA: $P<0.001$ ). Significant pair-wise contrasts: TH and M greater than NC $(P<0.001)$ on Physical Symptoms and Harm Avoidance; $\mathrm{TH}$ greater than $\mathrm{M}$ and $\mathrm{NC}$, and $\mathrm{M}$ greater than NC $(P<0.001)$ on Social Anxiety (see text for details).
CDI, and CPRS was too small for the rates to reach statistical significance (Table 3 ).

\section{Temperament of children with headache}

EAS scale showed that TH children had higher Emotionality and Shyness scores than M children, who did not differ from NC. M children also had higher Sociability scores than TH and NC children (Table 2).

\section{Temperament of first-degree relatives}

The EAS scores of the parents and siblings of the probands of this study are shown in Table 4 . Mothers 
of TH children had higher Emotionality scores than $\mathrm{M}$ or NC $(P<0.001)$, and lower levels of Activity than the other two groups. Fathers of TH and M children had higher levels of Activity than NC $(P<0.05)$. No statistically significant differences among the siblings of the three groups were found after adjustment for multiple comparisons.

\section{Discussion}

We found that indices of behavioural and emotional difficulties (CBCL) and of anxiety (MASC), depressive (CDI) and hyperactivity symptoms were elevated among clinically referred children suffering from $\mathrm{TH}$ or $\mathrm{M}$ compared with normal peers (Table 2). Most headache patients, however, had behavioural and psychological scores within the normative, non-pathological range (Table 3). The results confirm a significant association between childhood headache and presence of symptoms of emotional and behavioural challenges than children without headache, and are consistent with previous reports $(12,29-33)$. Future prospective research is needed to determine if behavioural and psychological problems antecede the onset of headache, emerge concurrenly with headache symptoms, or follow the manifestation of headache.

We also found that indices of global, internalizing and externalizing symptoms and hyperactivity were higher among TH children than M children, while depression and anxiety scores did not differ between the two headache groups (Tables 2 and 3). The TH group had higher temperamental traits of emotionality and shyness, and less sociability, than $\mathrm{M}$ (Table 2). A higher emotionality score were also found among the parents and siblings of TH children (Table 4). High scores of emotionality and shyness can be considered symptoms of 'behavioural inhibition' $(34,35)$.

School-age children who present with this trait are often irritable, shy, fearful and introverted. Different studies suggest that this temperamental trait increases the vulnerability to depressive and multiple anxiety disorders $(36,37)$. High Emotionality and Shyness scores on the EAS were reported in youths with anxiety with or without depression, and in their parents and siblings (38).

Taken together, these data suggest that children clinically referred for TH may have, as a group, more behavioural, emotional and temperamental difficulties than children referred for M. Although only a relatively small proportion of headache patients had scores that were actually in the psychopathological range based on normative references, the higher scores indicate the presence of significantly more subclinical behavioural and emotional difficulties than in normal controls.

This finding seems to be in contrast with the conclusions of a recently reported epidemiological study in Finland, which found that psychiatric symptoms tended to be more strongly associated with $\mathrm{M}$ than with $\mathrm{TH}$, without any difference, however, in anxiety symptoms (12). The difference in findings can be explained by the fact that our sample was clinically referred and not population based. Our results derived from children who were not representative of children in the general population, but of children who were clinically referred for treatment of primary headache.

One can only speculate on why clinically referred children with TH may be more likely to present with psychological symptoms than clinically referred children with $\mathrm{M}$. It is possible that TH children with concurrent anxiety, depression, behavioural disturbances, or excessive shyness and emotionality are more likely to be clinically referred than $\mathrm{TH}$ children without these psychopathological and temperamental features. The symptoms of $\mathrm{M}$, in contrast, may be so distinctive and acute as to trigger clinical referral even in the absence of emotional and behavioural problems.

The interface between headache and psychological symptoms remains unclear and the design of this study does not allow us to distinguish headacheinduced psychological difficulties from pre-existing symptoms. The association between headache and indices of behavioural and psychological difficulties that were elevated compared with normal controls, but on average still in the normative range, suggests that headache and psychological symptoms may be related, thus underscoring the need for a broad and comprehensive approach to children referred for headache. Further research is needed to elucidate the mechanism underlying the observed association.

This study has a number of important limitations that must be taken into account in interpreting the data. Most notably, the sample size is relatively small and more appropriate for exploratory analyses than for definitive hypothesis testing. Furthermore, the sample was entirely derived from a single university clinic and may not reflect other academic and nonacademic settings. As already pointed out, this was a clinically referred sample and not intended to be representative of children with headache in the general population. Finally, symptom scores were entirely derived from self-report assessment scales completed by the parents or the children themselves. While these rating scales have been shown to be 
valid instruments for screening children with psychiatric disorders, formal diagnoses of psychiatric disorders cannot be inferred. Since higher scores of Emotionality were found for TH children and their parents, based on parental report, it cannot be excluded that the informant's emotionality affected the ratings of the child, resulting in over-reporting of emotional and behavioural symptoms. Future studies should include data from informants other than the parents or the child, such as, for instance, teacher and clinician ratings.

In conclusion, in a clinically referred sample, both $\mathrm{TH}$ and $\mathrm{M}$ were significantly associated with elevated indices of behavioural and emotional symptoms, including anxiety and depression. This association was stronger for TH than for M. TH children were also more likely that $\mathrm{M}$ to have temperamental traits of shyness and irritability. Larger, more representative, and prospective studies of clinically referred children with headache are needed to clarify the relationship between type of headache and psychological difficulties or temperamental traits.

\section{References}

1 Egger HL, Angold A, Costello EJ. Headaches and psychopathology in children and adolescents. J Am Acad Child Adolesc Psychiatry 1998; 37:951-8.

2 Abu-Arefeh I, Russell G. Prevalence of headache and migraine in schoolchildren. BMJ 1995; 309:765-9.

3 Mortimer MJ, Kay J, Jaron A. Epidemiology of headache and childhood migraine in an urban general practice using ad hoc, Vahlquist and IHS criteria. Dev Med Child Neurol 1992; 34:1095-101.

4 Sillanpää M. Prevalence of headache in prepuberty. Headache 1983; 23:10-4.

5 Stang PE, Osterhaus JT. Impact of migraine in the United States: data from the National Health Interview Survey. Headache 1993; 33:29-35.

6 Egermark-Eriksson I. Prevalence of headache in Swedish schoolchildren. Acta Paediatr Scand 1982; 71:135-40.

7 Headache Classification Committee of the International Headache Society. Classification and diagnostic criteria for the headache disorders, cranial neuralgias and facial pain. Cephalalgia 1988; 8 (Suppl. 7):10-73.

8 Venable VL, Carlson CR, Wilson J. The role of anger and depression in recurrent headache. Headache 2001; 41:2130.

9 Holmes WF, MacGregor A. Migraine related disability. Neurology 2001; 56:S13-9.

10 Pine DS, Cohen P, Brook J. The association between major depression and headache: results of a longitudinal epidemiological study in youth. J Child Adolesc Psychopharmacol 1996; 6:153-64.

11 Passchier J, Orlebeke JF. Headaches and stress in schoolchildren and epidemiological study. Headache 1985; 5: 167-76.

12 Anttilla P, Sourander A, Metsähonkala L, Aromaa M,
Helenius H, Silanpää M. Psychiatric symptoms in children with primary headache. J Am Acad Adolesc Psychiatry 2004; 43:412-9.

13 Balottin U, Nicoli F, Pitillo G, Ferrari Ginevra O, Borgatti $\mathrm{R}$, Lanzi G. Migraine and tension headache in children under 6 years of age. Eur J Pain 2004; 8:307-14.

14 Guidetti V, Galli F, Fabrizi P, Giannantoni AS, Napoli L, Bruni O, Trillo S. Headache and psychiatric comorbidity: clinical aspects and outcome in an 8-year follow-up study. Cephalalgia 1998; 18:455-62.

15 Merikangas KR, Angst K, Isler H. Migraine and psychopathology: results of the Zurich cohort study of young adults. Arch Gen Psychiatry 1990; 47:849-53.

16 Merikangas KR, Merikangas JR, Angst J. Headache syndromes and psychiatric disorders: association and familial transmission. J Psychiatr Res 1993; 27:197-210.

17 Waldie KE, Poulton R. Physical and psychological correlates of primary headache in young adulthood: a 26 year longitudinal study. J Neurol Neurosurg Psychiatry 2002; 72:86-92.

18 Merikangas KR, Stevens DE, Angst J. Headache and personality: results of a community sample of young adults. J Psychiatr Res 1993; 27:187-96.

19 Breslau N. Psychiatry comorbidity in migraine. Headache 1998; 18 (Suppl. 22):56-61.

20 Stronks DL, Tulen JH, Pepplinkhuizen L, Verheij R, Mantel GW, Spinhoven P, Passchier J. Personality traits and psychological reactions to mental stress of female migraine patients. Headache 1999; 19:566-74.

21 Lanzi G, Zambrino CA, Ferrari- Ginevra O, Termine C, D'Arrigo S, Vercelli P et al. Personality traits in childhood and adolescent headache. Cephalalgia 2001; 21:53-60.

22 Headache Classification Subcommittee of the International Headache Society. International classification of headache disorders, 2nd edition. ICHD-II. Cephalalgia 2004; 24 (Suppl. 1):9-160.

23 Achenbach TM, Eofbrock C. Manual for the child behaviour checklist. Burlington, VA: University of Vermont 1983.

24 Achenbach TM. Manual for the CBCL/4-18 and profile. Burlington, VA: Department of Psychiatry, University of Vermont 1991.

25 Kovacs M. The Children's Depression Inventory: a selfrated depression scale of school-aged youngsters. Pittsburgh: University of Pittsburgh School of Medicine 1982.

26 March JS. Multidimensional Anxiety Scale for Children. Tonawanda, NY: Multi-Health System Inc. 1997.

27 Conners CK. Conners Rating Scales-revised technical manual. North Tonawanda, NY: Multi-Health Systems Inc. 1997.

28 Buss AM, Plomin R. Temperament: early developing personality traits. Hillsdale, NJ: Lawrence Erlbaum Associates 1984.

29 Andrasik F, Kabella E, Qinn S, Attanasio V, Blanchard EB, Rosenblum EL. Psychological functioning of children who have recurrent migraine. Pain 1988; 34:43-52.

30 Cooper PJ, Bawden HN, Campfield PR, Campifield CS. Anxiety and life events in childhood migraine. Pediatrics 1987; 79:999-1004.

31 Cunningham SJ, McGrath PJ, Ferguson HB, Humphreys $\mathrm{P}, \mathrm{D}^{\prime}$ Astons J, Latter J et al. Personality and behavioural 
characteristics in paediatric migraine. Headache 1987; 217:16-20.

32 Guidetti V, Fornara R, Ottaviano S, Petrilli A, Seri S, Cortesi F. Personality inventory for children and childhood migraine: a case-controlled study. Headache 1987; 7:225-30.

33 Just U, Oelkers R, Bender S, Parzer P, Ebinger F, Weisbrod $\mathrm{M}$, Resch F. Emotional and behavioural problems in children and adolescents with primary headache. Cephalalgia 2003; 23:206-13.

34 Garcia-Coll C, Kagan J, Reznik JS. Behavioural inhibition in young children. Child Devel 1984; 55:1005-19.

35 Kagan J, Reznick JS, Clarke C, Snidman N, Garcia-Coll C.
Behavioural inhibition to the unfamiliar. Child Devel 1984; 55:2212-25.

36 Goodyer IM, Ashby L, Altham PME, Vize C, Cooper PJ. Temperament and major depression in 11-16 year olds. J Child Psychol Psychiatry 1993; 34:1409-23.

37 Kelvin RG, Goodyer IM, Altham PME. Temperament and psychopathology amongst siblings of probands with depressive and anxiety disorders. J Child Psychol Psychiatry $1996 ; 37: 543-50$.

38 Masi G, Mucci M, Favilla L, Brovedani P, Millepiedi S, Perugi G. Temperament in adolescent with anxiety and depressive disorders and their families. Child Psychiatry Human Dev 2003; 33:245-59. 